\section{Carbolic Acid in Boils and Felons}

To the Editor:-The treatment of boils, carbuncles, felons, in fact any local infection in its early stages by hypodermic injection of pure carbolic acid, has probably been used by others, but failing to find any mention of it in the literature, and having tried it on myself, I wish to report my method in order that it may be more widely known.

Having suffered from a boil on one hand and a carbuncle on the other, which ran their usual course, when others made their appearance, I was ready to experiment, and having tried without success to abort the first one by boring down into the center with a tooth pick wet with the acid, I went a step further with the second crop and injected the acid with a hypodermic syringe. To my great joy. the pain instantly ceased (one must have boils to appreciate this), did not begin again, and the hard lump soon disappeared. Since then I have used the method sufficiently to satisfy myself and others - latients-that it is a cure.

The method consists in injecting pure carbolic acid into the center of the inflamed spot, taking pains to introduce the needle not at the most prominent point of the swelling, but rather to one side where the skin is sound and shows no signs of pointing. It is not necessary to count the drops, enough to make the tissue tense.

It stops the pain instantly, destroys the germs, and is absorbed so slowly that no harm comes from it.

$$
\text { H. D. Gardner, Scranton, Pa. }
$$

\section{An Eye Bandage}

To the Editor:-In The Journal, March 27, page 1033, Dr. Morley describes "An Eye Bandage and Its Method of Application." This bandage has all the good qualities claimed for it, as a number of years' experience has convinced me. But it is only fair to state that it was invented many years ago by the late Dr. Russell Murdoch of Baltimore, and has been regularly used at the Baltimore Eye, Ear and Throat Charity Hospital. Dr. Morley will find Dr. Murdoch's description in the Ophthalmic Record of 1904 , and will I am sure regret having described as his own something which belongs to another.

Harry FriedenwaId, Baltimore.

\section{The Evolution of Refraction and Its Necessity}

T'o the Editor:-In The Jounval, March 27, page 1048, appeared a communication on the above subject by L. Haynes Buxton. Quoting from the third paragraph: "It was with much surprise that I read some of the statements contained in the paper by the late Dr. St. John Roosa, which appeared in The Journal, Feb. 13, page 543. My own personal and clinical experiences are so greatly at variance with the conclusions of Dr. Roosa that it is but just that they be recorded." This quotation, and, in fact, the whole letter, which gives admirable evidence of progressive thought conservatively expressed, so well represents not only my own views, but those of many other oculists, that it deserves a hearty endorsement.

Edward Lauder, Cleveland.

\section{Medical Education and State Boards of Registration}

\section{COMING EXAMINATIONS}

Alkaxsas: Three boards, each at Little Rock, April 13. Regula Sec. Dr. F. T. Murphy, Brinkley; Homeopathic Sec., Dr. I'. C Wiliams, Texarkana; Eclectle Sec., Dr. A. J. Widener, Little Rock. District of Columbia: Washington, April 13-16. Sec., Dr. George C. Ober, 210 B St., S. E.

ILLINoIS: Northwestern University Bldg., Chicago, April 15-17. Sec., Dr. J. A. Egan, Springfield.

New Mexico: Santa Fe. April 12. Sec., Dr. J. A. Massie.

OrLahoma: Guthrie, April 13. Sec. Dr. Frank 13. Davis, Enid.

Wes'r VIRGixia: Huntington, April 13-15. Sec., Dr. H. A.

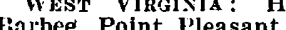

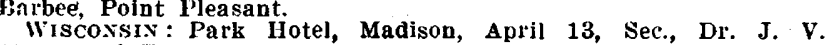
stevens, Jefteison.
COUNCIL ON MEDICAL EDUCATION

Fifth Annual Conference, held at Chicago, April 5

The Chairman, Dr. Ar'thur DeAn Bevas, Chicago, presiding

The fifth annual conference of the Council on Medical Education of the American Medical Association was held at the Auditorium Hotel, Chicago, April 5. In his address Dr. Bevan reviewed briefly the past history of the Council and called attention to the most marked improvements in medical edu. cation. The work of the past year was reported by the secretary, Dr. N. P. Colwell, who gave some of the conditions found by the inspection of medical colleges and also gave in detail the status of medical education at the present time.

Reports were then presented by the chairman of the ten subcommittees on medical curriculum, as follows:

1. ANatomy, INCLUDixg Histology AND EMBRYology-Dor. Charles R. Bardeen, Professor of Anatomy, University of Wisconsin, College of Medicine, Madison, Wis. iyon, Professor of Physiology, St. Louis University, School of Medicine, St. Louls.

3. Pathology and Bacteriology.-Dr. William 'T. Councilman, Professor of Pathology, Harvard Medical School, Boston.

4. Pharmacology, Toxicology and Therapeutics.-Dr. Tolald S. PharMacologr, Toxicologr AN and Materia Medica, Western Sollmann, Professor of Pharmacology and Materia 5. Medicine, Including Pediatrics AND Nervous ayd MENTat Dity of Louistana, New Orleans.

6. Surgery, Grineral And Special.-Dr. Charles $H$. Frazier, 6. SURGERY, GENERAL AND SPECIAL.-Dr. Charles H. Frazier,
Professor of Clinical Surgery, University of Pennsylvania, DepartProfessor of Clinical Surgery,
ment of Medicine. Philadelphia.

7. Onstetrics ANd Grincology.-Dr. J. B. Delee, Professor 7. Obstetrics and Grinconogy.-Dr. J. B. DeIfee, Profes
of Obstetrics, Northwestern University Medical School. Chicago. 8. Diseases of THE Ero, EAR. Nose and Throat.-Dr. George E. de Schweinitz, Professor of Ophthalmology. University of Pennsylvania, Department of Medicine, Philadelphia.

9. DeRMatology aNd Venereal Disfases.-Dr. William A. Pusey, Professor of Dermatology and Clinical Dermatology, College of Physicians and Surgeons, Chicago.

10. HYGiene, Medical JuRisprudence AND Medical EcoyomUniversity of Minnesota, College of Medicine, Minneapolis.

These reports recommended a curriculum which aggregated 4,400 hours. At a meeting of the chairmen held on the lay preceding the conference, these reports had been compared, a few duplications of courses were eliminated, and the total hours for each section reduced as follows:

SEBJECT. HoITS.

I. Anatomy, including histology and embryology ...... 700

II. Physiology and Physiologic Chemistry, including 80

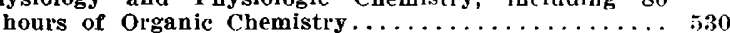

III. Pathology and Bacterílology ................. 500

IV. Pharmacology, Toxicology and Therapentics......... 240

$\checkmark$. Medicine, including Pediatrics and Nervous Diseases.... 890

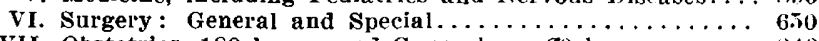

VII. Obstetrics, 180 hours, and Gynecology, 60 hours...... 240

VIIT. Diseases of the Eye, Ear, Nose and Throat. . . . . . . 140

IX. Dermatologn and Syphilis................ 90

X. Hygiene, Medical Economics and Medical Jurisprudence, ............................ 120

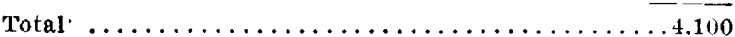

These figures were voted to represent the maximum requirement of a medical curriculum covering four years of 32 weeks each of actual work. It was the opinion of those present that the curriculum should not be made a hard and fixed requirement with which all colleges should comply. Its chief value was considered to be in its suggestiveness and from the fact that it represented an exhaustive study by over 100 leading medical educators, representing all the subjects included in the curriculum.

Dr. George W. Webster, president of the Illinois State Board of Health, gave an address on "The Medical Curriculum from the Standpoint of the State Board."

Dr. Fleming Carrow, of the Michigan State Board of Registration in Medicine, gave an address on "The Charactér of the State License Examination." In this address and the discussion which followed, it was shown that the best means of differentiation between the graduates of schools of the "quiz compend" type and those which have been trained in laboratories, dispensaries and hospitals would be to givein addition to written examinations-practical tests, wherein the applicant would be required to identify histologic speci mens, urinary casts, bacteria, etc., under the microscope, or 